\title{
Loeffler endocarditis with intracardiac thrombus: case report and literature review
}

\author{
Qian Zhang ${ }^{\dagger}$, Daoyuan $\mathrm{Si}^{\dagger}$, Zhongfan Zhang and Wenqi Zhang* ${ }^{*}$
}

\begin{abstract}
Background: Loeffler endocarditis is a relatively rare and potentially life-threatening heart disease. This study aimed to identify the characteristic features of Loeffler endocarditis with intracardiac thrombus on a background of hypereosinophilic syndrome (HES).

Case presentation: We described a 57-year-old woman with Loeffler endocarditis and intracardiac thrombus initially presenting with neurological symptoms, who had an embolic stroke in the setting of HES. After cardiac magnetic resonance (CMR), corticosteroids and warfarin were administered to control eosinophilia and thrombi, respectively. During a 10-month follow-up, the patient performed relatively well, with no adverse events. We also systematically searched PubMed and Embase for cases of Loeffler endocarditis with intracardiac thrombus published until July 2021. A total of 32 studies were eligible and included in our analysis. Further, $36.4 \%$ of recruited patients developed thromboembolic complications, and the mortality rate was relatively high (27.3\%). CMR was a powerful noninvasive modality in providing diagnostic and follow-up information in these patients. Steroids were administered in $81.8 \%$ of patients, achieving a rapid decrease in the eosinophil count. Also, $69.7 \%$ of patients were treated with anticoagulant therapy, and the thrombus was completely resolved in $42.4 \%$ of patients. Heart failure and patients not treated with anticoagulation were associated with poor outcomes.
\end{abstract}

Conclusions: Cardiac involvement in HES, especially Loeffler endocarditis with intracardiac thrombus, carries a pessimistic prognosis and significant mortality. Early steroids and anticoagulation therapy may be beneficial once a working diagnosis is established. Further studies are needed to provide evidence-based evidence for managing this uncommon manifestation of HES.

Keywords: Case report, Eosinophilia, Hypereosinophilic syndrome, Intracardiac thrombus, Loeffler endocarditis

\section{Background}

Hypereosinophilic syndrome (HES) is a rare disorder characterized by the elevation of blood eosinophil count $\left(>1.5 \times 10^{9} / \mathrm{L}\right)$ and multiple-organ involvement directly attributable to eosinophilia [1]. Loeffler endocarditis involves the abnormal infiltration of eosinophils into the endomyocardium, with subsequent tissue damage and fibrosis resulting from eosinophil degranulation,

\footnotetext{
*Correspondence: wenqi@jlu.edu.cn

${ }^{\dagger}$ Qian Zhang and Daoyuan Si both are the first authors

Department of Cardiology, China-Japan Union Hospital of Jilin University,

Xiantai Street No. 126, Changchun, Jilin, China
}

eventually leading to impaired diastolic function and restrictive ventricular filling [2]. It is divided into three pathological stages: necrotic stage, thrombotic stage, and fibrotic stage [3]. Notably, systemic thromboembolic events after mural thrombus formation and cardiac manifestations are considered to be common causes of morbidity and mortality in HES [4]. Considering the less recognized and high in-hospital mortality of patients with Loeffler endocarditis, data regarding their clinical presentations, courses, and outcomes remain uncertain. Furthermore, some evidence supports the effectiveness of steroids [5]. However, the guidelines and consensus statements regarding the treatment of Loeffler endocarditis 
are not clear. Therefore, this study aimed to present an unusual case of Loeffler endocarditis and intracardiac thrombus that caused cerebral embolic infarctions, and to conduct a systematic review on published cases of Loeffler endocarditis with intracardiac thrombus, summarizing clinical manifestations, diagnosis, treatments, and outcomes.

\section{Case presentation}

A 57-year-old woman with a known history of asthma and rheumatoid arthritis was admitted to the hospital after presenting with a headache and dyspnea for 1 week. The neurological examination showed vague speech, mild dysarthria, and limb muscle strength level 3 . Her brain magnetic resonance imaging showed multifocal acute-to-subacute ischemic lesions widely distributed over the bilateral cerebellar hemispheres and thalamus and parenchymal hemorrhage (Fig. 1). The initial laboratory findings were as follows: the white blood cell count was $20.43 \times 10^{9}$ (normal range, $4-10 \times 10^{9} / \mathrm{L}$ ), with increased peripheral eosinophilia at $12.04 \times 10^{9} / \mathrm{L}$ (normal range, $0.05-0.50 \times 10^{9} / \mathrm{L}$ ). Other inflammatory parameters showed an increased erythrocyte sedimentation rate of $79 \mathrm{~mm} / \mathrm{h}$ (normal range, $0-20 \mathrm{~mm} / \mathrm{h}$ ) and a C-reactive protein level of $95.4 \mathrm{mg} / \mathrm{L}$ (normal range, $0-8 \mathrm{mg} / \mathrm{L}$ ). The patient was also positive for the

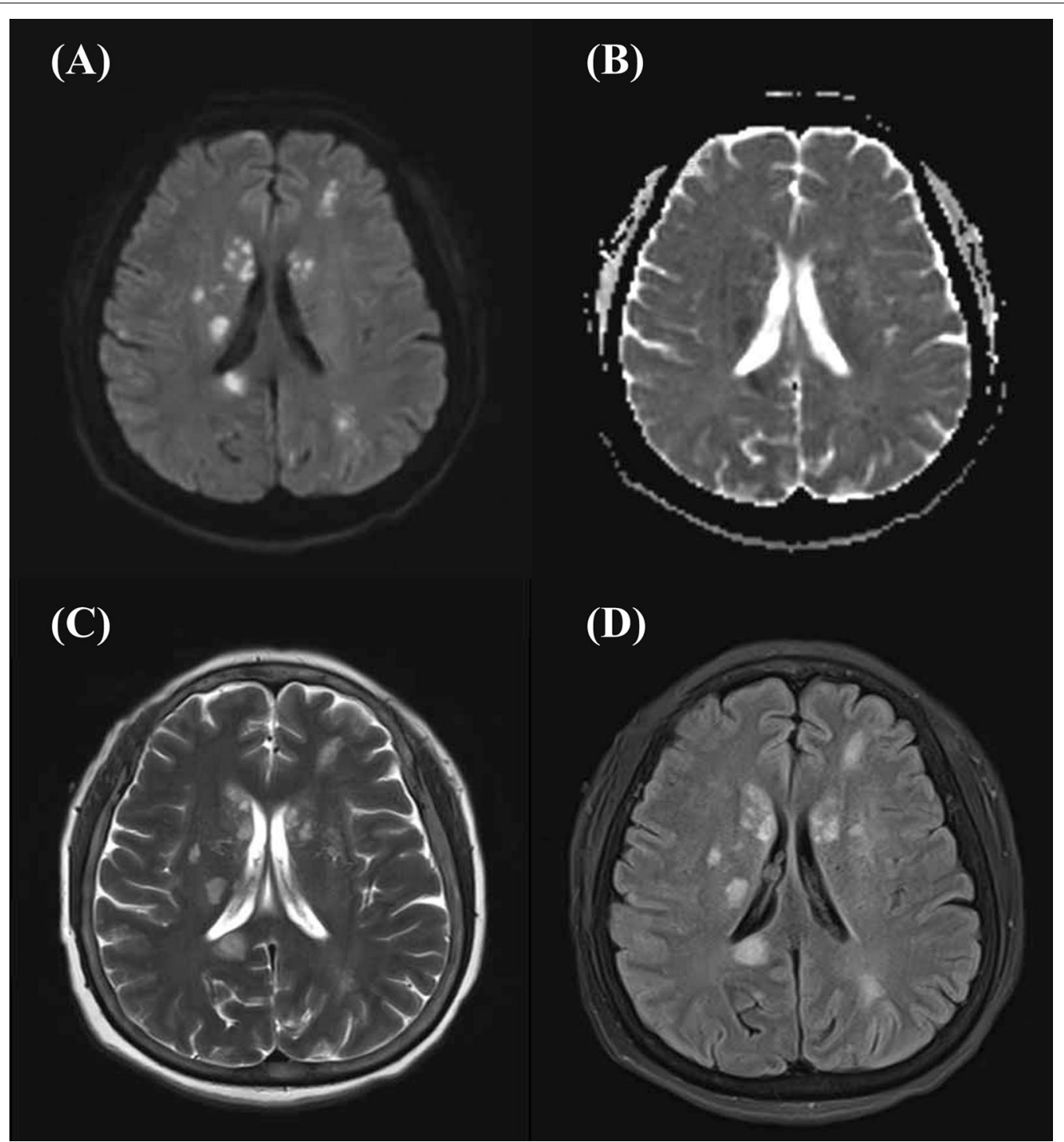

Fig. 1 Brain magnetic resonance imaging. A Diffuse-weighted image (DWI), B apparent diffusion coefficient (ADC) map, C T2-weighted image, and $\mathbf{D}$ fluid attenuated inversion recovery (FLAIR) image. Multifocal lesions of high intensity on DWI and ADC maps showed low values. There were multiple T2 high signal lesions in bilateral cerebral white matter 
anti-antineutrophilic perinuclear antibody (pANCA). Other specific markers related to autoimmune diseases, such as anti-dsDNA and anti-Sm, rheumatoid factorare were all negative. Her travel history was unremarkable. Her hospital course was further complicated by severe shortness of breath and elevated cardiac enzyme levels (cTnI: $14.10 \mathrm{ng} / \mathrm{mL}, \mathrm{CK}-\mathrm{MB}$ : $41.9 \mathrm{U} / \mathrm{L}$, NT-proBNP: $28,700 \mathrm{ng} / \mathrm{mL}$ ), which prompted an extensive cardiac workup. The electrocardiogram showed T-wave inversions in leads II, III, and aVF (Fig. 2). Two-dimensional echocardiography (Fig. 3A) showed that the systolic function of the heart was within the normal range, which was found to be $59 \%$ by the Simpson method. A thickened left ventricular (LV) endocardium with markedly solid echo could be seen, and a diagnosis of LV thrombus formation was suggested. Severe mitral regurgitation

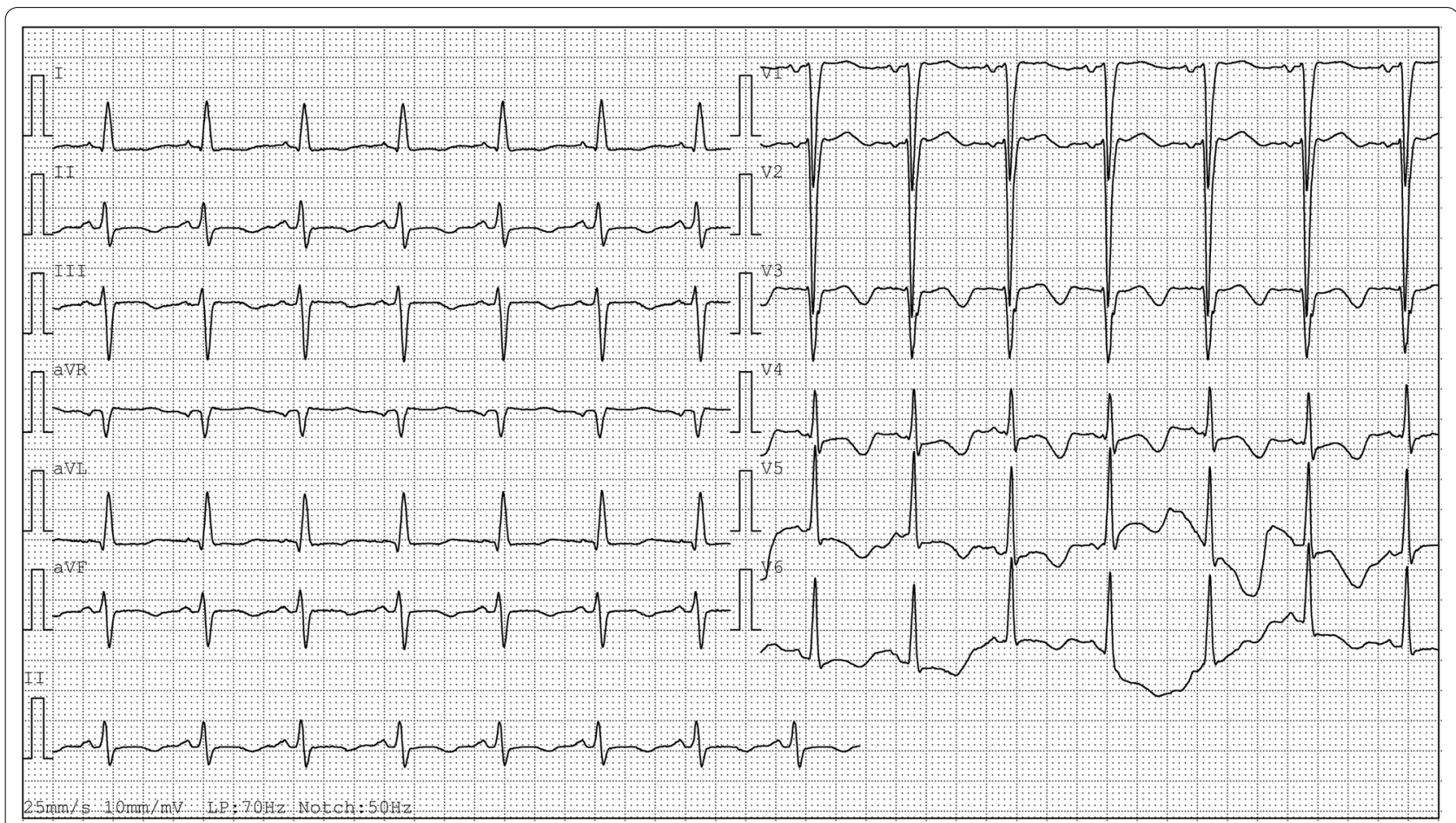

Fig. 2 Electrocardiogram: normal sinus rhythm, T wave inversion in leads II, III, aVF, V3,V4, V5, V6

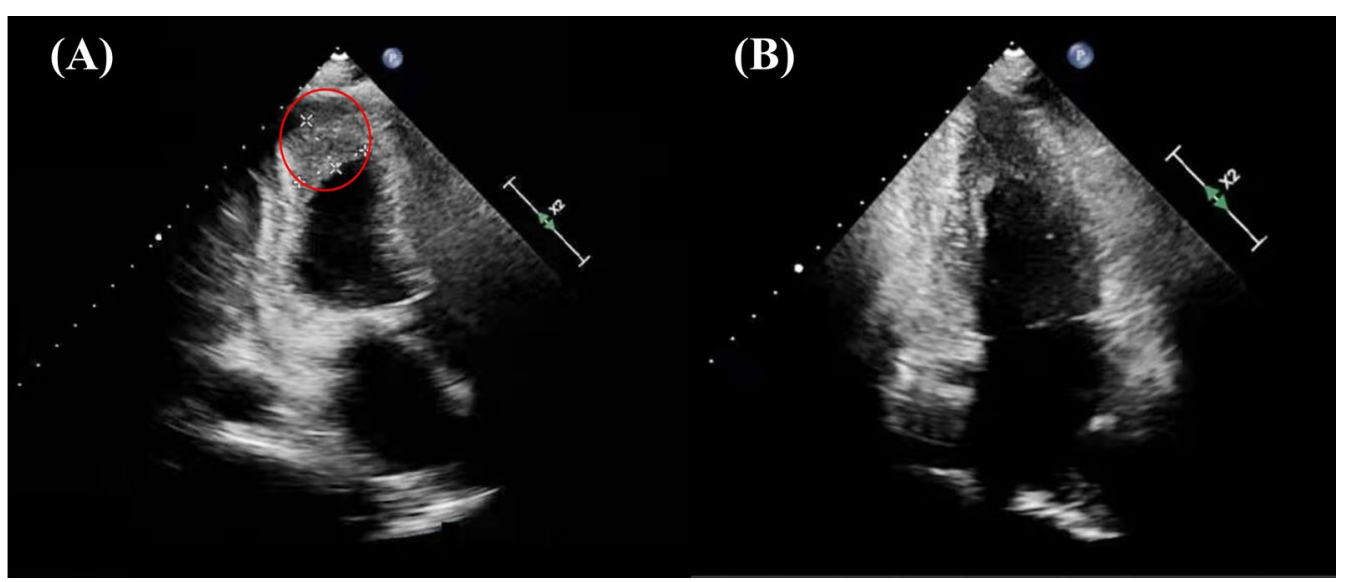

Fig. 3 A Apical four-chamber view of the transthoracic echocardiogram showing thickened left ventricular endocardium and left ventricular thrombus formation (red circle). B Ten-month follow-up echocardiographic imaging after treatment showing thickening of the left ventricular apex and suspicion of apical thrombus 
and moderate tricuspid regurgitation were noted. A small amount of pericardial fluid was also present $(4.6 \mathrm{~mm})$. We further excluded other causes of eosinophilia, such as malignancy, autoimmune diseases, and drug reactions. The parasites were negative in stool culture. In the peripheral blood smear, most of the granulocytes were normal, with no clonal proliferation or primordial cells. Further diagnostic clarification was required. The cardiac magnetic resonance (CMR) confirmed the presence of a thrombus measuring approximately $1.5 \times 1.7 \mathrm{~cm}$ in the apex of the LV, which, we believed, was the source of cerebral embolization. Gadolinium-enhanced CMR showed striated delayed enhancement between the apex and the papillary muscles restricted to the endocardium, with decreased diastolic function (Fig. 4), which was consistent with extensive endomyocardial fibrosis. Endocardial biopsy was recommended as the diagnostic gold standard to verify the histopathologic features. However, considering the risk of this invasive operation, the patient refused.

Based on the diagnosis of Loeffler endocarditis with LV thrombus, an intravenous bolus of a corticosteroid [prednisolone $1 \mathrm{mg} /(\mathrm{kg} \cdot$ day)] was initiated, followed by $40 \mathrm{mg}$ per day orally, which was prescribed as a definitive line of therapy. The blood tests showed significantly decreased eosinophil counts and percentages after another 2 days, along with a normalized cTnT level. The patient was treated with rivaroxaban to dissolve the thrombus, but the thrombus did not shrink after 3 months. Then, warfarin was added as antithrombotic therapy until followup. She was doing relatively well, and no adverse events occurred during a 10-month follow-up period. The echocardiography showed apical hypertrophy, and a suspected thrombus still existed (Fig. 3B). Therefore, CMR (Fig. 5) was repeated, which revealed the complete resolution of
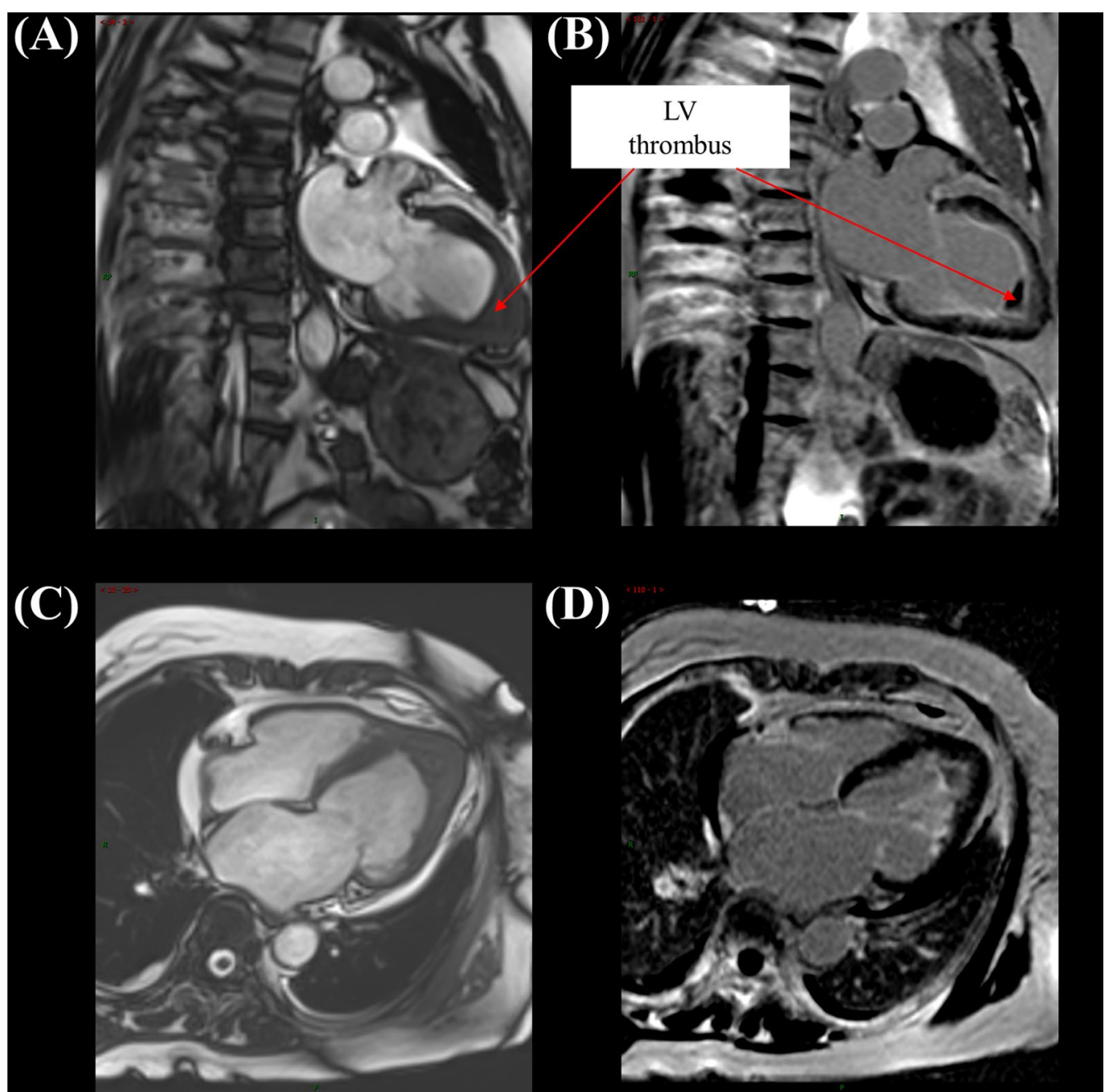

Fig. 4 A, C Early gadolinium enhancement imaging demonstrating a hypointense filling defect at the left ventricular apex. B, D Late gadolinium enhancement imaging demonstrating a large left ventricular apical thrombus and hyperenhancement indicative of endomyocardial fibrosis 


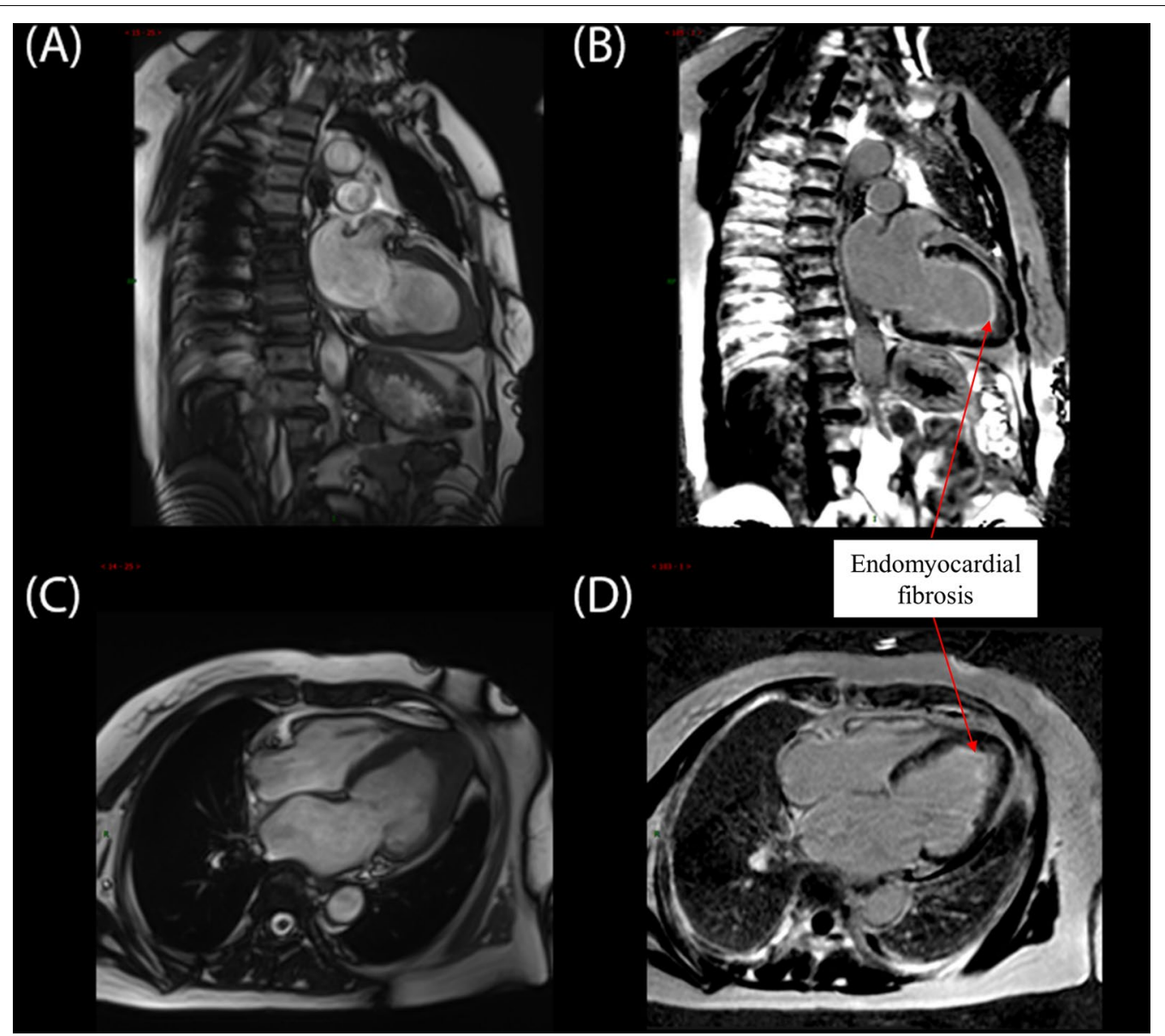

Fig. 5 At the 10-month follow-up, early and late gadolinium enhancement imaging demonstrating left ventricular apical thrombus resolution and endomyocardial fibrosis still existing after treatment

the apical thrombus and apical hypertrophy. However, no clear regression of endomyocardial fibrosis was observed. The timeline table is shown in Table 1.

\section{Literature search strategy}

For the literature review, we searched the PubMed and Embase for relevant studies, including all case reports and case series, published until June 1, 2021. The database was created using the search phrases "Loeffler endocarditis," "hypereosinophilic syndrome," and "thrombus." Studies that described Loeffler endocarditis related to thrombus formation were selected. Patients with specific diseases, including tropical endomyocardial fibrosis, Churg-Strauss syndrome, eosinophilic pneumonia, and clear heart disease combined with thrombus, were excluded. Cases were selected only if sufficient data were available for each case series. Two authors extracted and verified the data independently, and any differences were resolved through discussion. A total of 33 cases were identified. We also used the reference lists of articles published in English for the manual search. The clinical characteristics, complete blood counts, echocardiograms, CMR, treatment monitoring, and clinical follow-up were reviewed.

\section{Results}

We initially identified 477 articles using the aforementioned search strategy. A total of 33 [6-37] cases of Loeffler endocarditis associated with endoventricular thrombus were found. The epidemiological data, clinical manifestations, diagnostics, treatments, and outcomes are summarized in Table 2. The incidence of embolic stroke was $36.4 \%$ among patients with thrombi. The median age of patients was 44 years (IQR: 26-60 years), and the male-to-female ratio was 13:20. At admission, the most common presenting complaint was dyspnea (63.64\%), followed by fever (30.30\%), nervous system symptoms (18.18\%), chest pain (15.15\%), fatigue (15.15\%), abdominal symptoms (12.12\%), cough (6.06\%), and palpitations $(6.06 \%)$. At presentation, $82.0 \%$ of cases presented 
Table 1 Time line table from presentation to the last follow up

\begin{tabular}{|c|c|c|c|c|}
\hline & In hospital & 5 days after treatment & 4-month follow-up & $\begin{array}{l}\text { 10-month } \\
\text { follow-up }\end{array}$ \\
\hline \multicolumn{5}{|l|}{ Laboratory findings } \\
\hline WBC $\left(10^{9} / L\right)$ & 20.43 & 11.94 & 5.5 & 7.85 \\
\hline Eosinophilia $\left(10^{9} / \mathrm{L}\right)$ & 12.04 & 6.53 & 0.28 & 0.08 \\
\hline $\mathrm{cTnl}(\mathrm{ng} / \mathrm{mL})$ & 14.10 & 0.35 & 0.01 & NA \\
\hline NT-proBNP (ng/mL) & 28,700 & 22,300 & 3230 & NA \\
\hline $\operatorname{ESR}(\mathrm{mm} / \mathrm{h})$ & 79 & NA & NA & NA \\
\hline CRP (mg/L) & 95.4 & NA & NA & NA \\
\hline \multicolumn{5}{|l|}{ Echocardiography } \\
\hline LVEF, \% & 59 & 64.3 & 58 & 60 \\
\hline Thrombus size (mm) & $16.5^{*} 16.4$ & $24^{*} 18$ & $23 * 9$ & NA \\
\hline \multicolumn{5}{|l|}{ Treatments } \\
\hline Steroid & $\begin{array}{l}1 \mathrm{mg} / \mathrm{kg} / \text { day (intravenous } \\
\text { bolus) }\end{array}$ & $40 \mathrm{mg}$ & NA & NA \\
\hline Antithrombotic & rivaroxaban & Warfarin & Warfarin & NA \\
\hline
\end{tabular}

WBC, White blood cell; ESR, erythrocyte sedimentation rate; CRP, c-reactive protein; LVEF, left ventricular ejection fraction; NA, not available

with an unremarkable electrocardiogram, and $24.24 \%$ of cases had increased troponin levels. Subsequently, common echocardiographic findings included mitral regurgitation (42.42\%) and aortic regurgitation (4\%); $15 \%$ of patients had the involvement of two valves. A large number of cardiac structures were affected in these patients; however, the ejection fraction was well maintained. Pericardial effusions were observed in $18.18 \%$ of patients. Myocardial fibrosis and endoventricular thrombus were usually detected using delayed-enhancement gadolinium imaging. In terms of management, steroid therapy was the most common therapeutic modality $(81.8 \%)$, and immunosuppression was added in three cases $(10 \%)$.

In most patients, warfarin was started simultaneously for anticoagulant therapy. Patients who had Loeffler endocarditis with evidence of intracardiac thrombus detected by echocardiography or CMR, and one patient taking warfarin, had bleeding. One (3.1\%) patient $(3.1 \%)$ [26] received heart transplantation, whereas two (6.1\%) patients $[15,18]$ underwent surgical excision of right ventricular (RV) and LV thrombus and fibrosis and mitral valve replacement. Eight patients died from cerebral embolus [28, 34, 37] (37.5\%), heart failure [31, 36] (25\%), and bacterial sepsis $[12,15,36](37.5 \%)$. The cause of death was not clarified in one patient. Three patients $[18,26,31]$ were readmitted with severe congestive heart failure. Heart failure $(P=0.008)$ and the absence of anticoagulation treatment $(P=0.021)$ were more common pessimistic outcomes (Table 3 ). The thrombus was completely resolved in $42.4 \%$ of patients, and no further events were reported after the hospital discharge follow-up.

\section{Discussion and conclusion}

We described a case presenting with embolic strokes secondary to Loeffler endocarditis with intracardiac thrombus. Also, we provided data based on a series of published cases to summarize the clinical presentation, diagnostic findings, treatment, and outcomes of patients with intracardiac thrombus-proven Loeffler endocarditis. The mortality was found to be high $(27.3 \%)$ in these recruited patients, and patients with heart failure and those without anticoagulation treatment were associated with poor outcomes.

Cardiac involvement was frequently reported to be related to Loeffler endocarditis in HES, which was characterized by eosinophilic myocardial infiltration and necrosis in the acute necrotic stage. This damage was followed by a chronic fibrotic stage that involved the formation of an intracardiac thrombus with a frequent preference for the apex. This eventually led to restrictive cardiomyopathy and congestive heart failure, which portended an unfavorable prognosis. Our results showed that patients who had Loeffler endocarditis with endoventricular thrombus had a wide age distribution; the disease occurred in patients aged as young as 4 years and as old as 74 years. Women were often more affected than men. Elevated serum troponin levels were found both in the case we described and in most cases we recruited. This might be due to the release of toxic cationic proteins from degranulating eosinophils or pump failure or vascular damage caused by myocardial necrosis [38]. Cardiac markers might be sensitive indicators of persistent eosinophils related to myocardial damage [39]. In addition, echocardiography can provide useful information, such 


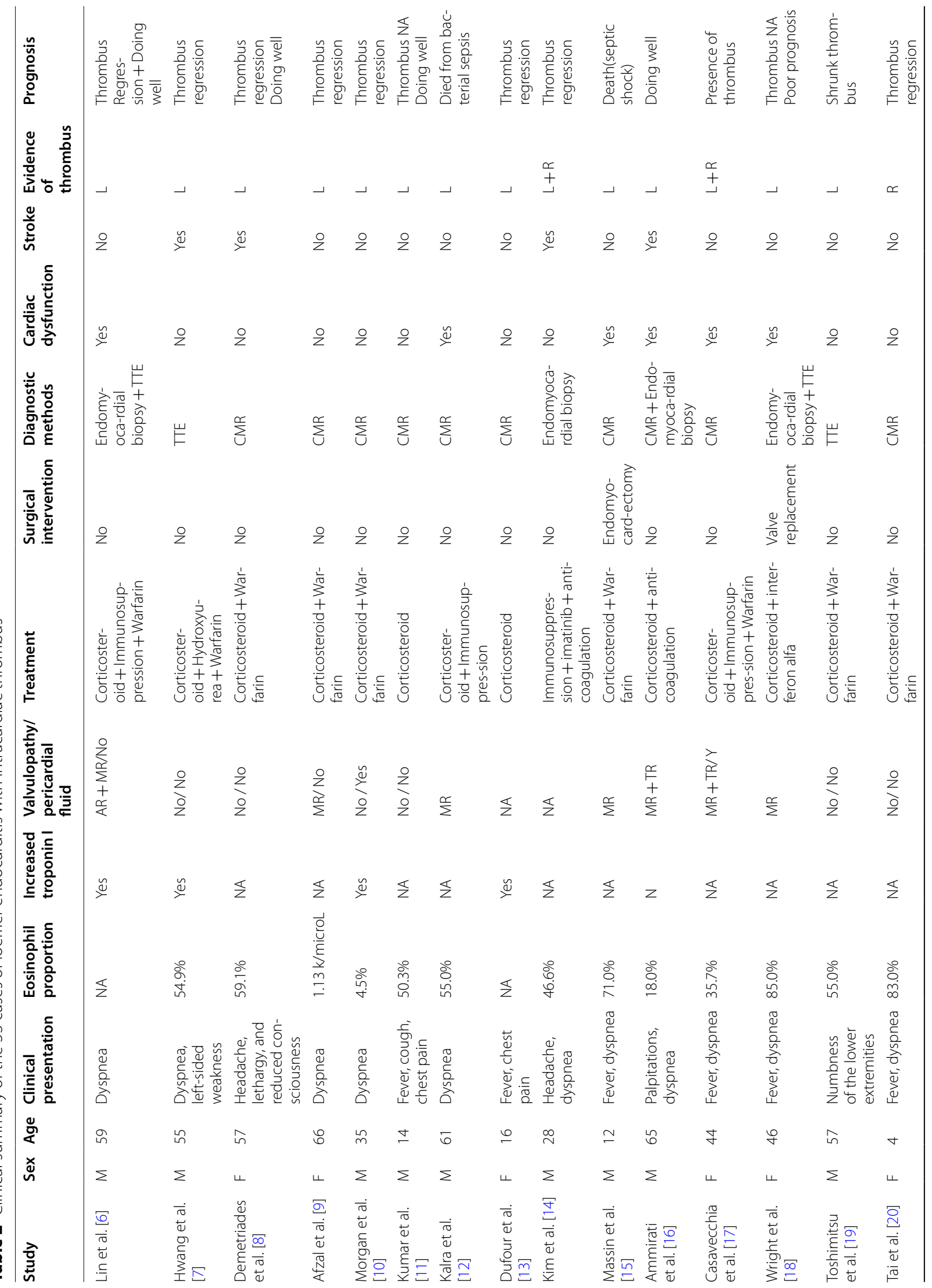




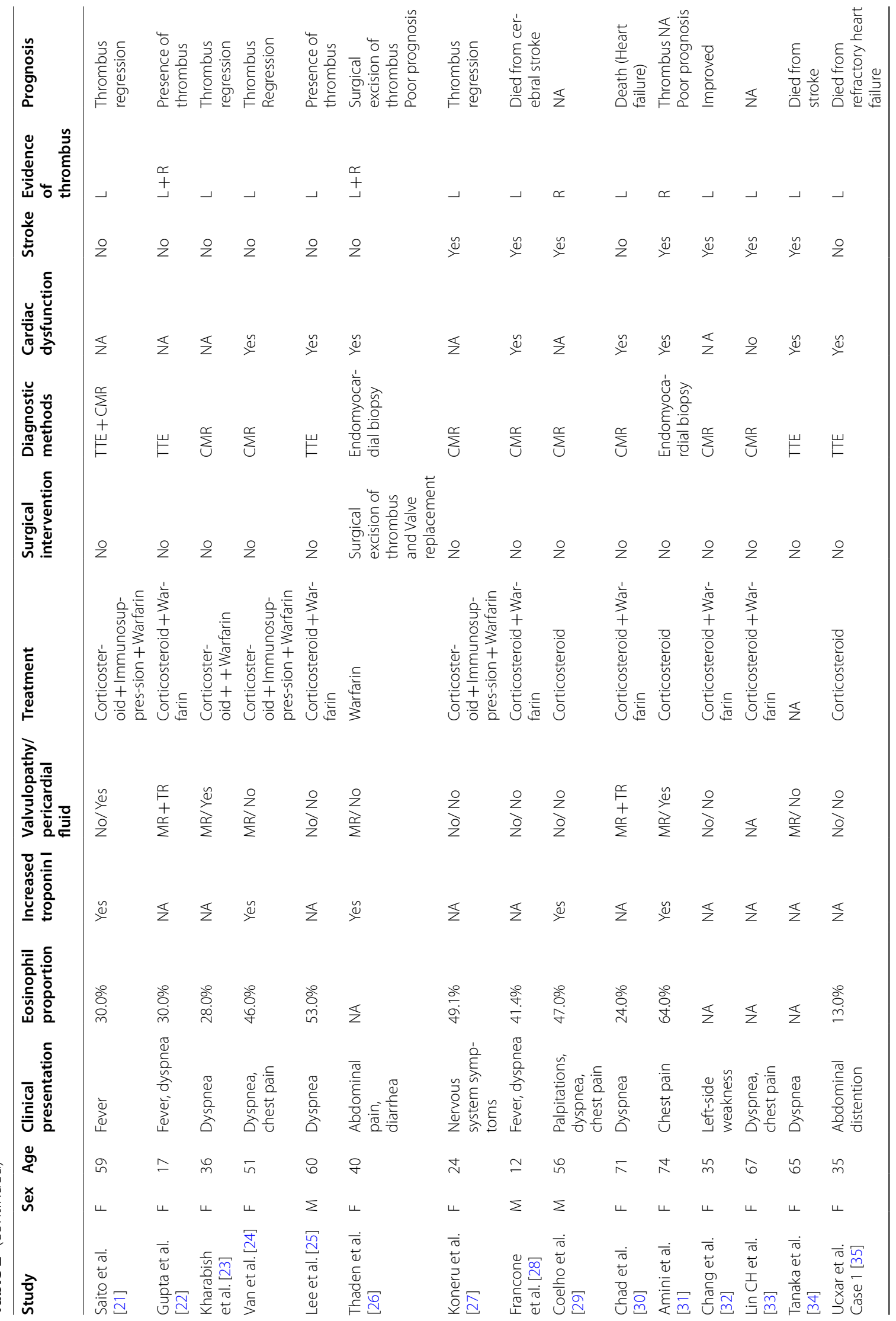




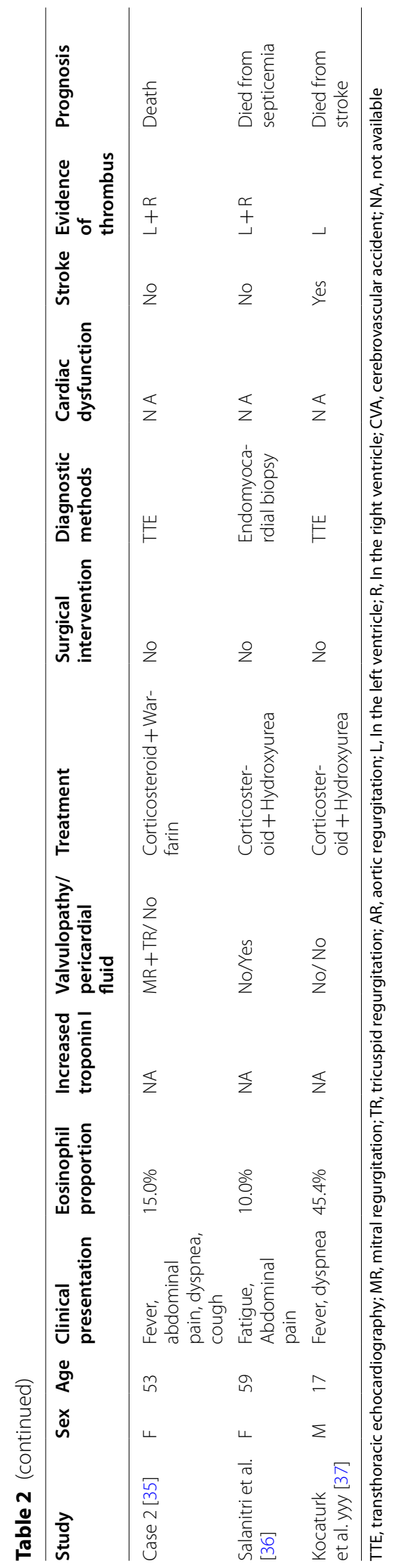


Table 3 Comparison between those with favorable and poor outcomes (2 cases not available)

\begin{tabular}{llll}
\hline & $\begin{array}{l}\text { Favorable } \\
\text { outcomes } \\
(\mathbf{n}=\mathbf{1 9})\end{array}$ & $\begin{array}{l}\text { Poor } \\
\text { outcomes } \\
(\mathbf{n}=\mathbf{1 2})\end{array}$ & $\boldsymbol{p}$ value \\
\hline Mean age & 43.1 & 45.4 & $0.681^{\ddagger}$ \\
Male & 3 & 9 & $0.002^{\S}$ \\
Heart failure & 5 & 9 & $0.008^{\S}$ \\
Stoke & 6 & 4 & $0.919^{\S}$ \\
Without steroid & 1 & 2 & $0.296^{\S}$ \\
Without antithrombotic & 3 & 7 & $0.021^{\S}$ \\
\hline
\end{tabular}

${ }^{\ddagger} p$ value was computed by Independent samples $t$-test

${ }^{\S} p$ value was computed by Fisher's exact test

as endomyocardial thickening, left and RV thrombus formation, and valvular regurgitation [40]. Of note, Loeffler endocarditis with a small thrombus in the thrombolysis stage might be difficult to diagnose using echocardiography and is sometimes confused with apical hypertrophy, such as that in our case. CMR can clearly identify apical thrombus and diffuse subendocardial fibrosis [41]. Consistent with a significant number of patients, the diagnosis of our case depended on the presence of HES in combination with cardiac involvement on CMR. Hence, if the diagnosis of Loeffler endocarditis with thrombus is under suspicion, CMR is quite informative. Endomyocardial biopsy remains the gold standard but is fraught with risks, such as sampling errors or iatrogenic embolism [42]. Furthermore, the presence of intracardiac thrombus can increase the risk of thromboembolism during an endomyocardial biopsy.

The goals for the treatment of Loeffler endocarditis are to reduce potentially eosinophil-mediated end-organ damage and prevent adverse thrombotic events. Our limited literature showed that $33.3 \%$ of patients who had Loeffler endocarditis with intracardiac thrombus developed thromboembolic complications, and the mortality rate was 27.3\%. Previous studies showed that thromboembolic disorders associated with Loeffler endocarditis were particularly difficult to control, despite anticoagulation therapy with warfarin, and embolic complications still appeared. One mechanism might involve the release of eosinophilic granular proteins from eosinophils [43], which could neutralize thrombomodulin via electrostatic binding, resulting in thromboembolism. Consistent with the aforementioned findings, thrombus regression occurred in 14 patients (42.4\%) after treatment with heparin or vitamin K antagonists both in our reported patient and patients included in this review. The risks of embolic events and mortality in these patients were much higher than those in patients with LVT caused by acute myocardial infarction; however, the rate of thrombus resolution in the recruited patients was relatively lower $[44,45]$. The poor outcome suggests that once we identify patients with LVT in clinical practice, HES with cardiac involvement should be taken into consideration. Consistent with our case, several case series demonstrated that most patients who received steroid therapy had hematologically normalized eosinophilia, and cardiac symptoms improved significantly. However, determining the preferred therapy other than corticosteroid therapy as the initial treatment of patients was also the essential step, such as patients with known imatinib-sensitive mutations and myeloproliferative HES. Additional immunosuppressive treatment with cyclophosphamide or azathioprine, as well as other cytotoxic agents or interferon-alpha, is usually reserved for patients with corticosteroid treatment failure. In our study, although one patient received endomyocardial stripping treatment, unfortunately, hypereosinophilia relapsed after 2.5 years. Valve replacement for five patients with severe valvular regurgitation provided considerable benefits. Limited experience with valve replacement/repair and endomyocardial stripping in Loeffler's study. In addition, consistent with other cases, our study showed that warfarin might have a clear therapeutic benefit in anticoagulation for Loeffler endocarditis with intracardiac thrombus.

Our study was limited by the small number of patients. Also, all data were derived from published cases, leading to publication bias. However, keeping in mind the rarity of Loeffler endocarditis, large-scale prospective or retrospective studies might be more difficult to conduct. Furthermore, the real mortality rate remains difficult to estimate, and cases not critical or with nonspecific symptoms are recorded at a lower rate. Therefore, mortality might be overestimated.

Loeffler endocarditis with intracardiac thrombus is rare, but the mortality is high. Our study highlighted the importance of CMR in establishing the diagnosis and monitoring treatment in Loeffler endocarditis. Early treatment with corticosteroids after excluding secondary causes without delay may be beneficial for these patients. In addition, late recurrence may occur, and long-term follow-up is required.

\section{Abbreviations}

HES: Hypereosinophilic syndrome; LV: Left ventricular; RV: Right ventricular.

\section{Acknowledgements}

Not applicable.

\section{Authors' contributions}

QZ cared for the patient and drafted the manuscript. ZZ performed the literature search and analysed the data, DS critically revised the manuscript, and WZ provided consultation and coordination of the manuscript. All authors reviewed and approved the final manuscript. 


\section{Funding}

This work was supported by grants from Science and Technology of Jilin Province (20210204199YY and 20200801076GH). The funding body had no role in the design or writing of the study.

\section{Availability of data and materials}

All the data discussed in the manuscript are included in this published article.

\section{Declarations}

\section{Ethics approval and consent to participate}

This case report was approved by the Medical Ethics Committee of the ChinaJapan Union Hospital of Jilin University. The patient consented to participate the study.

\section{Consent for publication}

Written informed consent was obtained from the patients for publication.

\section{Competing interests}

The authors have no conflicts of interest to disclose.

Received: 7 October 2021 Accepted: 21 December 2021

Published online: 28 December 2021

\section{References}

1. Valent P, Klion AD, Horny HP, Roufosse F, Gotlib J, Weller PF, et al. Contemporary consensus proposal on criteria and classification of eosinophilic disorders and related syndromes. J Allergy Clin Immunol. 2012;130(3):607-12.e9.

2. Alam A, Thampi S, Saba SG, Jermyn R. Loeffler endocarditis: a unique presentation of right-sided heart failure due to eosinophil-induced endomyocardial fibrosis. Clin Med Insights Case Rep. 2017;10:1179547617723643. https://doi.org/10.1177/1179547617723643.

3. Mankad R, Bonnichsen C, Mankad S. Hypereosinophilic syndrome: cardiac diagnosis and management. Heart. 2016;102(2):100-6.

4. Podjasek JC, Butterfield JH. Mortality in hypereosinophilic syndrome: 19 years of experience at Mayo Clinic with a review of the literature. Leuk Res. 2013;37(4):392-5.

5. Caforio AL, Pankuweit S, Arbustini E, Basso C, Gimeno-Blanes J, Felix SB, et al. European Society of Cardiology Working Group on Myocardial and Pericardial Diseases. Current state of knowledge on aetiology, diagnosis, management, and therapy of myocarditis: a position statement of the European Society of Cardiology Working Group on Myocardial and Pericardial Diseases. Eur Heart J. 2013;34(33):2636-48, 2648a-2648d. https:// doi.org/10.1093/eurheartj/eht210.

6. Lin WC, Huang KC, Hsiung MC, Feng AN. Loeffler's endocarditis in a patient with a new diagnosed Churg-Strauss syndrome (CSS): a case report. Caspian J Intern Med. 2021;12(1):107-10. https://doi.org/10. 22088/cjim.12.1.107.

7. Hwang JW, Kim H, Cho SW, Shin YC, Kim HS, Cho YJ, et al. Idiopathic hypereosinophilic syndrome with intracardiac atypical linear-shaped and floating thrombus presenting as embolic cerebral infarction. J Cardiol Cases. 2020;23(5):193-7.

8. Demetriades P, Speke L, Wilson L, Khan JN. When multimodality cardiac imaging saves the day: rare cause of embolic strokes. BMJ Case Rep. 2020;13(1): e232786. https://doi.org/10.1136/bcr-2019-232786.

9. Afzal S, Ahmed T, Saleem T, Chan A. Loeffler's endocarditis and the diagnostic utility of multimodality imaging. Cureus. 2020;12(8): e10061. https://doi.org/10.7759/cureus.10061.

10. Morgan H, Zaidi A, Anderson R, Goodfellow R, Ellis G. New breathlessness in a young patient with rheumatoid arthritis. Br J Hosp Med (Lond). 2019;80(10):612-3.

11. Kumar P, Chandrashekhara SH, Kumar S, Malhi AS. Loeffler's endocarditis with isolated left ventricular involvement on cardiac MRI. BMJ Case Rep. 2019;12(4): e227642. https://doi.org/10.1136/bcr-2018-227642.

12. Kalra DK, Park J, Hemu M, Goldberg A. Loeffler endocarditis: a diagnosis made with cardiovascular magnetic resonance. J Cardiovasc Imaging. 2019;27(1):70-2.
13. Dufour $\mathrm{M}$, Cochet $\mathrm{H}$. Both left ventricular papillary muscles necrosis, an eosinophylic lymphoblastic leukemia revealed by endomyocardial fibrosis. Presse Med. 2018:47(2):185-9.

14. Kim DS, Lee S, Choi CW. Loeffler endocarditis in chronic eosinophilic leukemia with FIP1L1/PDGFRA rearrangement: full recovery with low dose imatinib. Korean J Intern Med. 2018;33(3):642-4.

15. Massin MM, Jacquemart C, Damry N. Paediatric presentation of cardiac involvement in hypereosinophilic syndrome. Cardiol Young. 2017:27(1):186-8.

16. Ammirati E, Sirico D, Brevetti L, Scudiero L, Artioli D, Pedrotti P, et al. The key clues to reach the diagnosis of Loeffler endomyocardial fibrosis associated with eosinophilic granulomatosis with polyangiitis. J Cardiovasc Med (Hagerstown). 2017;18(10):831-2.

17. Casavecchia G, Gravina M, Correale M, Totaro A, Macarini L, Di Biase M, et al. Cardiac magnetic resonance imaging for the diagnosis and followup of Loeffler's endocarditis. J Allergy Clin Immunol. 2017;139(3):1055-7.

18. Wright BL, Butterfield JH, Leiferman KM, Gleich GJ. Development of eosinophilic endomyocardial disease in a patient with episodic angioedema and eosinophilia. J Allergy Clin Immunol Pract. 2016;4(2):336-7.

19. Tsugu T, Nagatomo Y, Yamada Y, Mahara K, Miura H, Murata M. The significance of early screening with echocardiography in eosinophilic granulomatosis with polyangiitis. J Med Ultrason. 2016;43(4):527-31. https://doi.org/10.1007/s10396-016-0728-7.

20. Tai CP, Chung T, Avasarala K. Endomyocardial fibrosis and mural thrombus in a 4-year-old girl due to idiopathic hypereosinophilia syndrome described with serial cardiac magnetic resonance imaging. Cardiol Young. 2016;26(1):168-71.

21. Saito Y, Okada S, Funabashi N, Kobayashi Y. ANCA-negative eosinophilic granulomatosis with polyangitis (EGPA) manifesting as a large intracardiac thrombus and glomerulonephritis with angionecrosis. BMJ Case Rep. 2016;2016:bcr2016216520. https://doi.org/10.1136/bcr-2016-216520.

22. Gupta A, Ananthakrishna R, Rao DPV, Bhat P, Nanjappa MC. Hematological dyspnea: a rare cause with gratifying recovery. J Cardiol Cases. 2015;12(3):83-6.

23. Kharabish A, Haroun D. Cardiac MRI findings of endomyocardial fibrosis (Loeffler's endocarditis) in a patient with rheumatoid arthritis. J Saudi Heart Assoc. 2015;27(2):127-31.

24. Van Dongen IM, van Kraaij DJW, Schalla S, Brunner-La Rocca HP, Driessen RGH. Severe mitral regurgitation caused by eosinophilic endocarditis. J Cardiol Cases. 2014;10(3):108-10.

25. Lee KG, Chuah MB, Tang HC, Chua TS. Hypereosinophilic syndrome with large intracardiac thrombus. Singapore Med J. 2014;55(8):e129-31.

26. Thaden J, Cassar A, Vaa B, Phillips S, Burkhart H, Aubry M, Nishimura R. Eosinophilic endocarditis and Strongyloides stercoralis. Am J Cardiol. 2013;112(3):461-2.

27. Koneru S, Koshy G, Sharp C, Khalafallah AA. Hypereosinophilic syndrome associated with ulcerative colitis presenting with recurrent Loeffler's endocarditis and left ventricular thrombus treated successfully with immune suppressive therapy and anticoagulation. BMJ Case Rep. 2013;2013:bcr201320019. https://doi.org/10.1136/bcr-2013-200919.

28. Francone M, lacucci I, Mangia M, Carbone I. Endomyocardial disease related to idiopathic hypereosinophilic syndrome: a cardiac magnetic resonance evaluation. Pediatr Cardiol. 2010;31(6):921-2.

29. Coelho-Filho OR, Mongeon FP, Mitchell RN, Blankstein R, Jerosch-Herold $\mathrm{M}$, Kwong RY. Images in cardiovascular medicine. Löffler endocarditis presenting with recurrent polymorphic ventricular tachycardia diagnosed by cardiac magnetic resonance imaging. Circulation. 2010;122(1):96-9.

30. Hilty KC, Koonce A, Ston W, Ramos-Duran R, Pyle LL, Batalis I, Taylor H. The role of cardiac MRI in the diagnosis and management of Loeffler's endocarditis: a case report with clinical and pathologic correlation. Open Cardiovasc Imaging J. 2010;2:10-3.

31. Amini R, Nielsen C. Eosinophilic myocarditis mimicking acute coronary syndrome secondary to idiopathic hypereosinophilic syndrome: a case report. J Med Case Rep. 2010;4:40. https://doi.org/10.1186/ 1752-1947-4-40.

32. Chang SA, Kim HK, Park EA, Kim YJ, Sohn DW. Images in cardiovascular medicine. Loeffler endocarditis mimicking apical hypertrophic cardiomyopathy. Circulation. 2009;120(1):82-5.

33. Lin CH, Chang WN, Chua S, Ko SF, Shih LY, Huang CW, et al. Idiopathic hypereosinophilia syndrome with loeffler endocarditis, embolic cerebral 
infarction, and left hydranencephaly: a case report. Acta Neurol Taiwan. 2009;18(3):207-12.

34. Tanaka H, Kawai H, Tatsumi K, Kataoka T, Onishi T, Nose T, et al. Surgical treatment for Löffler's endocarditis with left ventricular thrombus and severe mitral regurgitation: a case report. J Cardiol. 2006;47(4):207-13.

35. Uçar O, Gölbaşi Z, Yildirim N. Two cases of endomyocardial disease with hypereosinophilia in Turkey. Eur J Echocardiogr. 2005;6(5):379-81.

36. Salanitri GC. Endomyocardial fibrosis and intracardiac thrombus occurring in idiopathic hypereosinophilic syndrome. AJR Am J Roentgenol. 2005;184(5):1432-3.

37. Kocaturk H, Yilmaz M. Idiopathic hypereosinophilic syndrome associated with multiple intracardiac thrombi. Echocardiography. 2005;22(8):675-6.

38. Kleinfeldt T, Nienaber CA, Kische S, Akin I, Turan RG, Körber T, et al. Cardiac manifestation of the hypereosinophilic syndrome: new insights. Clin Res Cardiol. 2010;99(7):419-27.

39. Klion AD, Noel P, Akin C, Law MA, Gilliland DG, Cools J, et al. Elevated serum tryptase levels identify a subset of patients with a myeloproliferative variant of idiopathic hypereosinophilic syndrome associated with tissue fibrosis, poor prognosis, and imatinib responsiveness. Blood. 2003;101(12):4660-6.

40. Ommen SR, Seward JB, Tajik AJ. Clinical and echocardiographic features of hypereosinophilic syndromes. Am J Cardiol. 2000;86(1):110-3.

41. Syed IS, Martinez MW, Feng DL, Glockner JF. Cardiac magnetic resonance imaging of eosinophilic endomyocardial disease. Int J Cardiol. 2008;126(3):e50-2.

42. Fauci AS, Harley JB, Roberts WC, Ferrans VJ, Gralnick HR, et al. NIH conference. The idiopathic hypereosinophilic syndrome. Clinical, pathophysiologic, and therapeutic considerations. Ann Intern Med. 1982;97(1):78-92.

43. Mukai HY, Ninomiya H, Ohtani K, Nagasawa T, Abe T. Major basic protein binding to thrombomodulin potentially contributes to the thrombosis in patients with eosinophilia. Br J Haematol. 1995:90(4):892-9.

44. Zhang Z, Si D, Zhang Q, Qu M, Yu M, Jiang Z, et al. Rivaroxaban versus Vitamin K Antagonists (warfarin) based on the triple therapy for left ventricular thrombus after ST-Elevation myocardial infarction. Heart Vessels. 2021. https://doi.org/10.1007/s00380-021-01921-z.

45. Chen PF, Tang L, Yi JL, Pei JY, Hu XQ. The prognostic effect of left ventricular thrombus formation after acute myocardial infarction in the contemporary era of primary percutaneous coronary intervention: a meta-analysis. Eur J Intern Med. 2020;73:43-50.

\section{Publisher's Note}

Springer Nature remains neutral with regard to jurisdictional claims in published maps and institutional affiliations.

Ready to submit your research? Choose BMC and benefit from:

- fast, convenient online submission

- thorough peer review by experienced researchers in your field

- rapid publication on acceptance

- support for research data, including large and complex data types

- gold Open Access which fosters wider collaboration and increased citations

- maximum visibility for your research: over 100M website views per year

At BMC, research is always in progress.

Learn more biomedcentral.com/submissions 